\title{
Pengaruh Aktivitas Jalan Pagi Terhadap Tekanan Darah Pada Penderita Hipertensi Di Pusat Pelayanan Sosial Lanjut Usia Mappakasunggu Pare-Pare
}

\author{
*Andi Sani Silwanah' ${ }^{1}$, Rezky Aulia Yusuf ${ }^{2}$, Nyla Hatta ${ }^{1}$, \\ ${ }^{1}$ Sekolah Tinggi Ilmu Kesehatan Makassar \\ 2Ilmu Kesehatan Masyarakat, Fakultas Kesehatan Masyarakat, Universitas Muslim Indonesia \\ *Email: sani.silwanah@gmail.com
}

\begin{abstract}
ABSTRAK
Latar Belakang: Hipertensi adalah suatu keadaan dimana tekanan sistol dan diastol mengalami kenaikan yang melebihi batas normal tekanan (tekanan sistol diatas $140 \mathrm{mmHg}$ dan diastol diatas 90 $\mathrm{mmHg}$ ). Profil Dinas kesehatan provinsi Sulawesi Selatan pada tahun 2017, tekanan darah tinggi atau hipertensi di Sulawesi Selatan dengan kasus tertinggi, yaitu di kabupaten Selayar 32,49\%, kabupaten Soppeng $24,92 \%$ dan Takalar $14,82 \%$. Tujuan penelitian ini untuk mengetahui pengaruh aktivitas jalan pagi terhadap tekanan darah pada penderita hipertensi di Pusat Pelayanan Sosial Lanjut Usia (PPSLU) Mappakasunggu Pare-Pare.

Metode: Desain penelitian pre-experiment menggunakan one group pre-post test design dengan teknik purposive sampling. Analisa data diperoleh dengan observasi. Setelah data terkumpul dilakukan pemeriksaan kelengkapan dan pengolahan data, kemudian dilakukan analisis data univariat pada tiap-tiap variabel serta analisis bivariat untuk mengetahui pengaruh variabel independen (aktivitas jalan pagi) terhadap variabel dependen (hipertensi) dengan menggunakan uji statistik wilcoxon.

Hasil: Hasil penelitian ini menunjukkan dari 20 responden sebelum dilakukan aktivitas jalan pagi terdapat 12 reponden $(60,0 \%)$ tekanan darah sistol $140 \mathrm{mmHg}$ dan 15 responden $(75,0 \%)$ tekanan darah diastol $90 \mathrm{mmHg}$. Setelah dilakukan aktivitas jalan pagi terdapat 9 responden $(45,0 \%)$ pada tekanan darah sistol $140 \mathrm{mmHg}$ dan 8 responden (40,0\%) tekanan darah diastol antara 80 dan 90 $\mathrm{mmHg}$. Hasil analisa data diperoleh $\mathrm{p}=0.020(<0.05>)$.

Kesimpulan: Jalan pagi selama 30 menit dengan frekuensi 4 kali dalam seminggu sangat berpengaruh terhadap menurunnya tekanan darah sistolik dan diastolik pada lansia penderita hipertensi. Saran: diharapkan dapat menambah ilmu pengetahuan khususnya di bidang keperawatan gerontik.
\end{abstract}

Kata Kunci $\quad$ : Jalan Pagi, Hipertensi, Lansia 


\begin{abstract}
Background: Hypertension is a condition in which the systolic and diastolic pressures have increased beyond the normal limit of pressure (systolic pressure above $140 \mathrm{mmHg}$ and diastole above $90 \mathrm{mmHg}$ ). Profile of the South Sulawesi provincial health office in 2017, high blood pressure or hypertension in South Sulawesi with the highest cases, namely in Selayar district $32.49 \%$, Soppeng district $24.92 \%$ and Takalar $14.82 \%$. The purpose of this study was to determine the effect of morning walks on blood pressure in hypertensive patients at the Mappakasunggu Pare-Pare Elderly Social Service Center (PPSLU).

Methods: The pre-experimental research design used one group pre-post test design with purposive sampling technique. Data analysis obtained by observation. After the data was collected, the completeness check and data processing were carried out, then univariate data analysis was carried out on each variable and bivariate analysis to determine the effect of the independent variable (morning walk) on the dependent variable (hypertension) using the Wilcoxon statistical test.

Results: The results of this study indicate that out of 20 respondents before the morning walk, there were 12 respondents $(60.0 \%)$ systolic blood pressure of $140 \mathrm{mmHg}$ and 15 respondents (75.0\%) diastolic blood pressure of $90 \mathrm{mmHg}$. After the morning walk, there were 9 respondents $(45.0 \%)$ at systolic blood pressure of $140 \mathrm{mmHg}$ and 8 respondents $(40.0 \%)$ diastolic blood pressure between 80 and $90 \mathrm{mmHg}$. The results of data analysis obtained $\mathrm{p}=0.020(<0.05>)$.

Conclusion: Walking in the morning for 30 minutes with a frequency of 4 times a week greatly affects the reduction of systolic and diastolic blood pressure in elderly people with hypertension. Suggestion: hopefully it can add knowledge, especially in the field of gerontic nursing.
\end{abstract}

Keywords: Morning Walk, Hypertension, Elderly

\section{LATAR BELAKANG}

Lansia merupakan proses akhir dari perkembangan manusia. Proses akhir perkembangan ditandai dengan menurunnya fungsi imun tubuh termasuk penurunan sistem kardiovaskuler. Salah satu masalah yang dihadapi lansia pada penurunan fungsi kardiovaskuler adalah hipertensi ${ }^{5}$.

Lansia yang mengalami hipertensi merupakan proses alami yang ditandai dengan penurunan fisik. Rendahnya penderita hipertensi untuk berobat di karenakan hipertensi tidak menunjukkan gejala khas yang bisa dipakai sebagai peringatan dini. Hipertensi kini telah menjelma sebagai penyakit penyebab kematian nomor tiga setelah stroke dan tuberkulosis di negara Indonesia 9 .

Hipertensi adalah suatu keadaan dimana tekanan sistol dan diastol mengalami kenaikan yang melebihi batas normal tekanan (tekanan sistol diatas $140 \mathrm{mmHg}$ dan diastol diatas 90 mmHg). Berdasarkan data World Health
Organization (WHO), menyatakan bahwa terjadi peningkatan jumlah orang yang menderita hipertensi atau tekanan darah tinggi dari 600 juta pada tahun 1980 menjadi 1 milyar pada tahun 2008. Di perkirakan akan terus meningkat pada tahun 2020 sekitar 1,56 milyar orang dewasa akan hidup dengan hipertensi ${ }^{10}$.

Menurut American Heart Assocation (AHA), penduduk Amerika yang berusia di atas 20 tahun dan menderita hipertensi telah mencapai angka hingga 74,5 juta jiwa, namun hampir sekitar 90-95\% kasus tidak diketahui penyebabnya. Diperkirakan sekitar $80 \%$ kenaikan kasus hipertensi terutama terjadi di negara berkembang pada tahun 2025, dari jumlah 639 juta kasus ditahun 2000. Jumlah ini diperkirakan meningkat menjadi 1,15 miliar kasus di tahun $2025^{23}$.

Prevalensi hipertensi di Indonesia yang didapat melalui kuesioner terdiagnosis tenaga kesehatan sebesar 9,4\%, yang di diagnosis tenaga kesehatan atau sedang minum obat 
sebesar $9,5 \%$. Jadi, ada $0,1 \%$ yang minum obat tersendiri. Responden yang mempunyai tekanan darah normal tetapi sedang minum obat hipertensi sebesar $0,7 \%$. Jadi prevalensi hipertensi di Indonesia sebesar 26,5\% ${ }^{2}$.

Berdasarkan hasil Riset Kesehatan Dasar (RISKESDAS) tahun 2018 menunjukkan bahwa angka prevalensi Hipertensi hasil pengukuran pada penduduk usia $\geq 18$ tahun sebesar 34,1\%, tertinggi di Kalimantan Selatan $(44,1 \%)$, sedangkan terendah di Papua sebesar $(22,2 \%)$. Estimasi jumlah kasus hipertensi di Indonesia sebesar 63.309.620 orang, sedangkan angka kematian di Indonesia akibat hipertensi sebesar 427.218 kematian ${ }^{11}$.

Data Dinas Kesehatan Provinsi Sulawesi Selatan pada tahun 2014 terdapat penderita baru hipertensi esensial (primer) sebanyak 5.902 kasus, dengan penderita lama sebanyak 7.575 kasus, dengan kematian kasus 65 orang, jantung hipertensi dengan penderita lama 1.687 kasus, dan penderita baru 1.670 kasus dengan kasus kematian 24 orang, ginjal hipertensi penderita baru sebanyak 58 kasus, dengan penderita lama sebanyak 34 kasus dengan kematian 5 orang, jantung dan hipertensi sekunder dengan penderita lama sebanyak 2.082 kasus dan penderita baru sebanyak 2.081 kasus dengan kasus kematian 18 orang. Profil Dinas kesehatan provinsi Sulawesi Selatan pada tahun 2017, Tekanan darah tinggi atau hipertensi di Sulawesi Selatan dengan kasus tertinggi, yaitu di kabupaten Selayar 32,49\%, kabupaten Soppeng 24,92\% dan Takalar $14,82 \%{ }^{15}$.

Pada lansia penderita hipertensi diperlukan pengukuran tekanan darah yang rutin agar tekanan darahnya dapat terpantau dengan baik. Hipertensi dapat dicegah dengan menghindari faktor penyebab terjadinya hipertensi yaitu pengaturan pola makan, gaya hidup yang benar, menghindari kopi, merokok, dan alkohol, mengurangi konsumsi garam yang berlebihan dan aktivitas yang cukup seperti olahraga yang teratur ${ }^{16}$.

Telah banyak penelitian sebelumnya yang mendukung pernyataan bahwa aktivitas fisik berpengaruh terhadap tekanan darah pada hipertensi. Seperti, penelitian JE Martin dkk yang mengatakan bahwa latihan aerobik ringan dapat mengurangi tekanan darah sebesar 3,2
$\mathrm{mmHg}$ tekanan diastolik dan $5,7 \mathrm{mmHg}$ tekanan sistolik pada penderita hipertensi tanpa pengobatan. Penelitian serupa juga dilakukan oleh Fernando Dimeo dkk di Brasil tahun 2012 yang mengatakan bahwa yang mengatakan bahwa olahraga secara teratur dapat menurunkan tekanan darah sistolik sebesar 6 $\mathrm{mmHg}$ dan Diastolik sebesar $3 \mathrm{mmHg}$ pada penderita hipertensi yang resisten ${ }^{12}$.

Dari hasil penelitian yang dilakukan oleh Puspita tahun 2017 bahwa aktivitas jalan pagi memiliki pengaruh terhadap perubahan tekanan darah pada lansia dengan hipertensi. Melakukan olahraga secara teratur dapat menurunkan tekanan darah sistol 4-8 mmHg. Olahraga lebih banyak dihubungkan dengan pengobatan hipertensi karena olahraga isotonik (berjalan, bersepeda, jogging, aerobik) yang teratur dapat memperlancar peredaran darah sehingga dapat menurunkan tekanan darah ${ }^{16}$.

Dari Observasi awal yang dilakukan di Pusat Pelayanan Sosial Lanjut Usia Tresna Werdha Gau Mabaji Goa terdapat 23 orang lansia, namun yang menderita hipertensi ada 8 orang, setelah itu dilakukan lagi survei di Panti Werdha Theodora akan tetapi masih belum diberi izin untuk melakukan penelitian berhubung karena masih dalam tahap renovasi.

Sehingga peneliti bertujuan untuk melakukan penelitian di Pusat Pelayanan Sosial Lanjut Usia (PPSLU) Mappakasunggu Pare-Pare jumlah lansia pada tahun 2019 sebanyak 75 orang. Berdasarkan pada latar belakang tersebut, membuat peneliti tertarik untuk meneliti Pengaruh Aktivitas Jalan Pagi Terhadap Tekanan Darah Pada Lanjut Usia Di Pusat Pelayanan Sosial Lanjut Usia (PPSLU) Mappakasunggu Pare-Pare.

\section{BAHAN DAN METODE}

Jenis Penelitian ini adalah penelitian kuantitatif dengan menggunakan desain penelitian Pre-Exsperimental Design dengan rancangan penelitian One Group PretestPosttest Design. Desain penelitian ini dilakukan dengan cara sebelum diberikan perlakuan (treatment) variabel di observasi terlebih dahulu (pre test) setelah itu diberikan perlakuan (treatment) dan setelah treatment, dilakukan observasi (post test). 
Populasi dalam penelitian ini adalah semua pasien lansia yang berada di Pusat Pelayanan Sosial Lanjut Usia (PPSLU) Mappakasunggu Pare-Pare berjumlah 75 lansia.

Sampel dalam penelitian ini adalah sebanyak 20 lansia yang mengalami hipertensi di Pusat Pelayanan Sosial Lanjut Usia (PPSLU) Mappakasunggu Pare-Pare dengan pertimbangan dan kriteria tertentu.

Pengambilan sampel dalam penelitian ini menggunakan metode Nonprobability Sampling dengan teknik Purposive Sampling dimana cara pengambilan sampel untuk tujuan tertentu didasarkan pada suatu pertimbangan tertentu yang dibuat oleh peneliti berdasarkan ciri atau sifat populasi yang sudah diketahui sebelumnya.

Tehnik pengumpulan data yang dilakukan antara lain :

1. Sumber data

a. Data primer

Data primer diperoleh melalui teknik pengumpulan data dengan cara meggunakan lembar observasi. Observasi dilakukan sebelum (pre test) dan setelah (post test) pemberian aktivitas jalan pagi.

b. Data Sekunder

Pada penelitian ini data sekunder diperoleh dari Pusat Pelayanan Sosial Lanjut Usia (PPSLU) Mappakasunggu Pare-Pare berupa jumlah lansia yang menderita hipertensi.

\section{HASIL DAN PEMBAHASAN}

\section{Analisa Univariat}

\section{a. Karakteristik Responden}

Tabel 1. Karakteristik Responden Berdasarkan Umur, Jenis Kelamin, dan Aktivitas Jalan Pagi di Pusat Pelayanan Sosial Lanjut Usia Mappakasunggu Parepare Tahun 2019

\begin{tabular}{|c|c|c|}
\hline $\begin{array}{c}\text { Karakteristik } \\
\text { Responden }\end{array}$ & $\mathbf{n}$ & $\%$ \\
\hline \multicolumn{3}{|l|}{ Umur } \\
\hline 56-65 Tahun & 9 & 45,0 \\
\hline$>65$ Tahun & 11 & 55,0 \\
\hline \multicolumn{3}{|l|}{ Jenis Kelamin } \\
\hline Laki-laki & 8 & 40,0 \\
\hline Perempuan & 12 & 60,0 \\
\hline
\end{tabular}

\begin{tabular}{llc}
\hline $\begin{array}{l}\text { Aktivitas Jalan } \\
\text { Pagi }\end{array}$ & & \\
Ya (30 menit) & 10 & 50,0 \\
Tidak (<30 menit) & 10 & 50,0 \\
\hline \multicolumn{1}{c}{ Jumlah } & 20 & 100,0 \\
\hline
\end{tabular}

Sumber : Data Primer 2019

Tabel 1 di atas menunjukan bahwa dari 20 responden yang diteliti, untuk kategori umur yang paling banyak berada pada usia > 65 tahun sebanyak 11 responden $(55,0 \%)$ dan usia 56 - 65 tahun sebanyak 9 responden $(45,0 \%)$. Sedangkan berdasarkan jenis kelamin yang paling banyak berada pada jenis kelamin perempuan sebanyak 12 responden $(60,0 \%)$, dan jenis kelamin laki-laki sebanyak 8 responden $(40,0 \%)$. Kemudian untuk kategori aktivitas jalan pagi dengan durasi waktu 30 menit dan <30 menit jumlah respondennya sama masing-masing sebanyak 10 responden $(50,0 \%)$.

b. Distribusi responden berdasarkan nilai sistol pre test dan post test hari ke-4

Tabel 2. Distribusi Responden Berdasarkan Sistol Pre Test dan Post Test Lansia Hari Ke-4 di Pusat Pelayanan Sosial Lanjut Usia Mappakasunggu Kota Pare-Pare Tahun 2019

\begin{tabular}{|c|c|c|}
\hline Sistol (mmHg) & $\mathrm{n}$ & $\%$ \\
\hline \multicolumn{3}{|l|}{ Pre Test } \\
\hline 130 & 3 & 15,0 \\
\hline 140 & 12 & 60,0 \\
\hline 150 & 5 & 25,0 \\
\hline \multicolumn{3}{|l|}{ Post Test } \\
\hline 120 & 8 & 40,0 \\
\hline 130 & 3 & 15,0 \\
\hline 140 & 9 & 45,0 \\
\hline Jumlah & 20 & 100,0 \\
\hline
\end{tabular}

Sumber : Data Primer 2019

Tabel 2 diatas menunjukkan bahwa dari 20 responden lansia yang nilai sistol pre test yang terbanyak berada pada nilai $140 \mathrm{mmHg}$ sebanyak 12 responden $(65,0 \%)$ dan nilai sistol pre test yang sedikit berada pada nilai 130 mmHg sebanyak 3 responden $(15,0 \%)$. Sedangkan nilai sistol post test yang terbanyak berada pada nilai $140 \mathrm{mmHg}$ sebanyak 9 responden $(45,0 \%)$ dan nilai sistol post test yang paling sedikit berada pada nilai 130 mmHg sebanyak $3(15,0 \%)$. 
c. Distribusi responden berdasarkan nilai diastol pre test dan post test hari ke-4

Tabel 3. Distribusi Responden Berdasarkan Diastol Pre Test dan Post Test Lansia Hari Ke4 di Pusat Pelayanan Sosial Lanjut Usia Mappakasunggu Kota Pare-Pare Tahun 2019

\begin{tabular}{lcc}
\hline \multicolumn{1}{c}{ Diastol $(\mathbf{m m H g})$} & $\mathbf{n}$ & $\mathbf{\%}$ \\
\hline Pre Test & & \\
80 & 5 & 25,0 \\
90 & 15 & 75,0
\end{tabular}

\begin{tabular}{|c|c|c|}
\hline \multicolumn{3}{|l|}{ Post Test } \\
\hline 70 & 4 & 20,0 \\
\hline 80 & 8 & 40,0 \\
\hline 90 & 8 & 40,0 \\
\hline Jumlah & 20 & 100,0 \\
\hline
\end{tabular}

Sumber : Data Primer 2019

Tabel 3 diatas menunjukkan bahwa dari 20 responden lansia yang nilai diastol post test yang terbanyak berada pada nilai $90 \mathrm{mmHg}$ sebanyak 15 responden $(75,0 \%)$ dan nilai diastol pre test yang sedikit berada pada nilai $80 \mathrm{mmHg}$ sebanyak 5 responden $(25,0 \%)$. Sedangkan nilai diastol post test yang terbanyak berada pada nilai 80 dan $90 \mathrm{mmHg}$ masing-masing sama sebanyak 8 responden $(40,0 \%)$ dan nilai diastol post test yang paling sedikit berada pada nilai $70 \mathrm{mmHg}$ sebanyak 4 responden $(20,0 \%)$.

d. Distribusi frekuensi umur berdasarkan aktivitas jalan pagi dalam durasi waktu selama 30 dan $<30$ Menit

Tabel 4. Distribusi Frekuensi Umur Berdasarkan Aktivitas Jalan Pagi Dalam Durasi Waktu Selama 30 dan <30 Menit di PPSLU Mappakasunggu Kota Pare-Pare Tahun 2019

\begin{tabular}{ccccccc}
\hline \multirow{2}{*}{ Umur } & \multicolumn{4}{c}{ Aktivitas Jalan Pagi } & Jumlah \\
\cline { 2 - 7 } & $\begin{array}{c}\text { Durasi 30 } \\
\text { menit }\end{array}$ & $\begin{array}{c}\text { Durasi }<30 \\
\text { menit }\end{array}$ & & \\
\cline { 2 - 7 } & $\mathbf{n}$ & $\mathbf{\%}$ & $\mathbf{n}$ & $\mathbf{\%}$ & $\mathbf{n}$ & $\mathbf{\%}$ \\
\hline Usia 56-65 tahun & 10 & 50.0 & 0 & 0 & 10 & 50.0 \\
Usia >65 tahun & 0 & 0 & 10 & 50.0 & 10 & 50.0 \\
\hline Total & 10 & 50.0 & 10 & 50.0 & 20 & 100 \\
\hline
\end{tabular}

Sumber : Data Primer 2019

Berdasarkan tabel 4 diatas menunjukkan bahwa dari 20 responden terkait frekuensi umur dengan aktivitas jalan pagi dalam durasi waktu selama 30 dan $<30$ menit, terdapat responden yang berusia 56-65 tahun sebanyak
$10(50.0 \%)$ yang melakukan aktivitas jalan pagi dengan durasi 30 menit, dan responden yang berusia $>65$ tahun sebanyak $10(50.0 \%)$ yang melakukan aktivitas jalan pagi dengan durasi $<30$ menit.

\section{Analisa Bivariat}

Uji wilcoxon signed ranks test

Tabel 5. Pengaruh Aktivitas Jalan Pagi Terhadap Tekanan Darah Pada Penderita Hipertensi di Pusat Pelayanan Sosial Lanjut Usia Mappakasunggu Kota Pare-Pare Tahun 2019

\begin{tabular}{|c|c|c|}
\hline & $\begin{array}{c}\text { Tekanan } \\
\text { Darah } \\
\text { Sistol Pre } \\
\text { Test } \\
\text { Tekanan } \\
\text { Darah } \\
\text { Sistol } \\
\text { Post Test }\end{array}$ & $\begin{array}{c}\text { Tekanan } \\
\text { Darah } \\
\text { Diastol Pre } \\
\text { Test } \\
\text { Tekanan } \\
\text { Darah } \\
\text { Sistol } \\
\text { Post Test } \\
\end{array}$ \\
\hline Z & $-2.530^{\mathrm{a}}$ & $-2.333^{\mathrm{a}}$ \\
\hline Asymp. Sig. (2-tailed) & .011 & .020 \\
\hline
\end{tabular}

Sumber : Data Primer 2019

Berdasarkan tabel 5 di atas dapat dilihat hasil analisis data menggunakan uji Wilcoxon Signed Ranks Test untuk sistol nilai Z sebesar 2.530 dengan $p$ value $0.011=a<0.05$, sedangkan untuk diastol nilai $\mathrm{Z}$ sebesar -2.333 hasil tersebut dapat diketahui bahwa nilai Sig. 2-tailed atau $p$ value sebesar 0.020 lebih kecil dari tingkat kemaknaan $a=0.05(p=0.020<$ $a=0.05)$. Hasil ini menunjukkan berarti $\mathrm{H}_{\mathrm{o}}$ ditolak dan $\mathrm{H}_{\mathrm{a}}$ diterima, bahwa terdapat pengaruh aktivitas jalan pagi terhadap tekanan darah pada penderita hipertensi di pusat pelayanan sosial lanjut usia mappakasunggu pare-pare.

\section{PEMBAHASAN}

Berjalan kaki merupakan olahraga yang bersifat ringan, sederhana, murah dan mampu dilaksanakan oleh semua pasien hipertensi. Jalan pagi adalah aktivitas yang dilakukan manusia diwaktu pagi hari sebelum terbitnya matahari. Tujuannya untuk mengaktifkan kembali sel atau jaringan ditubuh dan untuk merefleksikan sendi-sendi otot pergelangan kaki dan tubuh untuk lebih bergerak, maka dari itu alangkah baiknya kalau keringat keluar dari dalam tubuh untuk menetralisirkan racun yang 
keluar dan tubuh akan jadi segar bugar sedari olahraga.

Ada 2 tekanan dalam tekanan darah yaitu tekanan sistolik dan tekanan diastolik. Tekanan sistolik adalah tekanan tertinggi karena jantung bilik kiri memompa darah ke arteri sedangkan tekanan diastolik adalah tekanan terendah saat jantung beristirahat atau rileks. Tekanan darah digambarkan sebagai rasio tekanan sistolik dan tekanan diastolik.

Seseorang penderita hipertensi yang melakukan aktivitas fisik jalan pagi atau olahraga setiap hari dapat memperkecil resiko terjadinya Hipertensi, demikian pula sebaiknya bila seseorang tidak pernah atau jarang melakukan aktivitas fisik atau olahraga setiap hari dapat meningkatkan resiko terjadinya Hipertensi ${ }^{1}$.

Berdasarkan hasil penelitian yang telah dilakukan yaitu dengan karakteristik responden di Pusat Pelayanan Sosial Lanjut Usia Mappakasunggu Kota Pare-Pare menunjukkan karakteristik berdasarkan umur lansia dari 20 responden $(100 \%)$ yang paling banyak adalah $>65$ tahun sebanyak 11 lansia 55,0\% dan paling sedikit adalah 56-65 tahun sebanyak 9 lansia $45,0 \%$. Berdasarkan jenis kelamin didapatkan bahwa dari 20 responden lansia $(100 \%)$ yang paling banyak yaitu perempuan 12 lansia $60,0 \%$ dan paling sedikit laki-laki sebanyak 8 lansia 40,0\%. Berdasarkan perlakuan aktivitas jalan pagi jumlah respondennya sama masingmasing sebanyak 10 lansia 50,0\% diantaranya kategori Ya yakni durasi waktu yang diberikan perlakuan jalan pagi selama 30 menit sebanyak 10 lansia 50,0\% sedangkan kategori Tidak yakni durasi waktu yang diberikan perlakuan jalan pagi selama $<30$ menit sebanyak 10 lansia $50,0 \%$.

Bertambahnya umur akan mempengaruhi aktivitas fisik seseorang. Sebagaimana hasil temuan Sulistiono (2015), umur merupakan dapat mempengaruhi kualitas dan kuantitas aktivitas fisik seseorang yang terkait dengan aktivitas fisik sehari-hari. Hal ini disebabkan karena bertambahnya umur akan disertai dengan penurunan kapasitas fisik berupa penurunan masa dan kekuatan otot, laju denyut jantung maksimal, peningkatan lemak tubuh, dan penurunan fungsi otak. Oleh sebab itu, orang yang berusia lanjut memiliki kecenderungan yang kurang untuk melakukan aktivitas fisik dan rentan dengan penyakit ${ }^{7}$.

Dalam penelitian ini hasil analisa menunjukkan dari 20 responden terkait frekuensi umur dengan aktivitas jalan pagi dalam durasi waktu selama 30 dan <30 menit, terdapat responden yang berusia 56-65 tahun sebanyak $10(50.0 \%)$ yang melakukan aktivitas jalan pagi dengan durasi 30 menit, dan responden yang berusia $>65$ tahun sebanyak 10 (50.0\%) yang melakukan aktivitas jalan pagi dengan durasi $<30$ menit.

\section{Tekanan Darah Pada Lansia Hipertensi Sebelum Jalan Pagi}

Tekanan darah manusia dapat diukur secara tidak langsung menggunakan tensimeter. Hasil pengukuran tekanan darah ditulis dalam dua angka, yaitu angka sistol dan diastol dalam satuan millimeter air raksa ${ }^{16}$. Berdasarkan hasil penelitian sebelum melakukan jalan pagi tekanan darah sistol yang terbanyak berada pada nilai $140 \mathrm{mmHg}$ sebanyak 12 responden sedangkan tekanan darah diastol yang terbanyak berada pada nilai $90 \mathrm{mmHg}$ sebanyak 15 responden.

Jika kita melakukan jalan pagi, maka tentunya kita akan menggerakkan kedua kaki dan mengayunkan lengan yang menunjukkan telah terjadi kerja otot. Olahraga akan memberikan pengaruh yang baik terhadap berbagai macam sistem yang bekerja didalam tubuh, salah satunya adalah sistem kardiovaskuler dimana dengan latihan fisik yang benar dan teratur akan terjadi efisiensi kerja jantung seperti melakukan aktivitas fisik berupa olahraga ringan seperti berjalan selama 30-60 menit dengan frekuensi 3-5 kali seminggu.

Berdasarkan hasil penelitian bahwa klasifikasi tekanan darah sebelum melakukan aktivitas jalan pagi dalam durasi waktu selama 30 menit yang paling banyak yakni TD sistol pre test yang hipertensi sebanyak 9 orang $(45,0 \%)$ dan paling sedikit yakni TD sistol pre test yang tidak hipertensi sebanyak 1 orang $(5,0 \%)$ sedangkan TD diastol pre test yang hipertensi sebanyak 7 orang $(35,0 \%)$ dan paling sedikit yakni TD diastol pre test yang tidak hipertensi sebanyak 3 orang $(15,0 \%)$, kemudian pada klasifikasi tekanan darah 
sebelum melakukan aktivitas jalan pagi dalam durasi waktu selama <30 menit yang paling banyak yakni TD sistol pre test yang hipertensi sebanyak 8 orang $(40,0 \%)$ dan paling sedikit yakni TD sistol pre test yang tidak hipertensi sebanyak 2 orang $(10,0 \%)$ sedangkan TD diastol pre test yang hipertensi sebanyak 8 orang $(40,0 \%)$ dan yang paling sedikit yakni TD diastol pre test yang tidak hipertensi sebanyak 2 orang (10,0\%).

Faktor umur juga sangat berpengaruh terhadap hipertensi, seperti yang ditunjukkan pada tabel 3 bahwa lebih dominan berumur yakni > 65 tahun sebanyak 11 orang $(55,0 \%)$. Hal ini sejalan dengan pendapat sesuai dengan teori Elshanti (2009) yang mengatakan bahwa bertambahnya umur seseorang maka semakin tinggi pula resiko akan terjadinya hipertensi. Insiden hipertensi meningkat seiring dengan bertambahnya umur dimana seseorang yang berumur diatas 60 tahun 50-60\% mempunyai tekanan darah lebih dari atau sama dengan 140/90 $\mathrm{mmHg}^{12}$.

\section{Tekanan Darah Pada Lansia Hipertensi Setelah Jalan Pagi}

Berdasarkan hasil penelitian sebagian lansia mengalami penurunan tekanan darah, hasil pengukuran tekanan darah sistol sesudah melakukan jalan pagi yaitu $120-130 \mathrm{mmHg}$ sebanyak 11 responden dan tekanan darah diastol sesudah melakukan jalan pagi yaitu 70$80 \mathrm{mmHg}$ sebanyak 12 responden.

Latihan jalan kaki memang sangat ringan dan sederhana, tetapi jika dilakukan dengan terprogram, sistematis dan terstruktur akan mendapat hasil positif terhadap tingkat kebugaran dan kesehatan. Artinya tidak jauh berbeda pengaruhnya dengan olahraga aerobik lainnya. Dalam pelaksanaan penelitian ini, latihan jalan kaki yang ditujukan untuk membantu menurunkan tekanan darah sistolik dan diastolik pada penderita hipertensi adalah dengan intensitas latihan 30 menit $^{24}$.

Setelah diberikan intervensi latihan jalan pagi pada responden, terdapat perubahan tekanan darah setelah jalan pagi terlihat perbedaannya ditabel 7 menunjukkan bahwa dari 20 responden terkait klasifikasi tekanan darah setelah melakukan aktivitas jalan pagi dalam durasi waktu selama 30 menit masing- masing sama yakni TD sistol post test yang tidak hipertensi sebanyak 10 orang $(50,0 \%)$ dan TD diastol post test yang tidak hipertensi sebanyak 10 orang $(50,0 \%)$ sedangkan klasifikasi tekanan darah setelah melakukan aktivitas jalan pagi dalam durasi waktu selama $<30$ menit yang paling banyak yakni TD sistol post test yang hipertensi sebanyak 9 orang $(45,0 \%)$ dan paling sedikit yakni TD sistol post test yang tidak hipertensi sebanyak 1 orang $(5,0 \%)$ sedangkan TD diastol post test yang hipertensi sebanyak 8 orang $(40,0 \%)$ dan yang paling sedikit yakni TD diastol post test yang tidak hipertensi sebanyak 2 orang $(10,0 \%)$.

Dari data diatas dapat di simpulkan bahwa masih terdapat peningkatan tekanan darah atau tekanan darahnya masih tetap dari sebelumnya setelah dilakukan intervensi (jalan pagi), tetapi lebih dominan berpengaruh jalan pagi selama 30 menit di bandingkan <30 menit. Jalan pagi yang dilakukan selama 30 menit dengan frekuensi 4 kali dalam seminggu dapat menurunkan tekanan darah sebanyak 20 $\mathrm{mmHg}$ pada sistolik dan $10 \mathrm{mmHg}$ diastolik sedangkan jalan pagi yang dilakukan selama <30 menit dengan frekuensi 3 kali dalam seminggu hanya dapat menurunkan tekanan darah sebanyak $10 \mathrm{mmHg}$ pada diastolik.

\section{Pengaruh Aktivitas Jalan Pagi Terhadap Tekanan Darah Pada Penderita Hipertensi}

Berdasarkan tabel 8 di atas dapat dilihat hasil analisis data menggunakan uji Wilcoxon Signed Ranks Test untuk sistol nilai Z sebesar 2.530 dengan $p$ value $0.011=a<0.05$, sedangkan untuk diastol nilai $\mathrm{Z}$ sebesar -2.333 hasil tersebut dapat diketahui bahwa nilai Sig. 2-tailed atau $p$ value sebesar 0.020 lebih kecil dari tingkat kemaknaan $a=0.05 \quad(p=0.020<$ $a=0.05)$. Hasil ini menunjukkan berarti $\mathrm{H}_{\mathrm{o}}$ ditolak dan $\mathrm{H}_{\mathrm{a}}$ diterima, bahwa terdapat pengaruh aktivitas jalan pagi terhadap tekanan darah pada penderita hipertensi di pusat pelayanan sosial lanjut usia mappakasunggu pare-pare.

Aktivitas fisik atau olahraga sangat mempengaruhi terjadinya hipertensi, dimana pada orang yang kurang aktivitas akan cenderung mempunyai frekuensi denyut jantung lebih tinggi sehingga otot jantung akan 
bekerja lebih keras pada tiap kontraksi. Makin keras dan sering otot jantung memompa maka makin besar tekanan yang dibebankan pada arteri. Makanya sangat dianjurkan berolahraga seperti jalan kaki, olahraga yang teratur dapat mengurangi stress, juga dapat menurunkan berat badan serta membakar lemak didalam darah dan memperkuat otot-otot jantung.

Hasil penelitian yang dilakukan oleh Khomarun menunjukkan bahwa tekanan darah pada lansia pre dan post pemberian intervensi aktivitas berjalan mengalami perbedaan yang bermakna, sehingga ada pengaruh aktivitas fisik jalan pagi terhadap penurunan tekanan darah pada lansia dengan hipertensi stadium I di Posyandu Lansia Desa Makamhaji. Begitu pula dengan hasil penelitian yang dilakukan Larasiska bahwa pengaruh jalan kaki terhadap penurunan tekanan darah pada lansia hipertensi terbukti kebenarannya ${ }^{12}$.

Surbakti (2014) menyatakan bahwa latihan jalan kaki apabila dilakukan dengan terprogram, sistematis dan terstruktur akan mendapat hasil yang positif. Dalam penelitian yang dilakukannya, latihan jalan kaki yang ditujukan untuk membantu menurunkan tekanan darah sistolik dan diastolik pada penderita hipertensi, dengan hasil yang diperoleh berupa pemeriksaan tekanan darah dengan sfigmomanometer (bentuk pengukuran ini dapat mendeteksi dan melihat seberapa besar tekanan darah) ${ }^{24}$.

Menurut asumsi peneliti berdasarkan dari hasil observasi yang telah dilakukan di Pusat Pelayanan Sosial Lanjut Usia Mappakasunggu Kota Pare-Pare setelah dilakukan aktivitas jalan pagi di dapatkan signifikan karena pada saat melakukan jalan pagi, lansia mengikuti sesuai petunjuk dan arahan yang telah diberikan. Dengan demikian lansia yang melakukan aktivitas jalan pagi dapat meningkatkan angka harapan hidup lansia sehingga derajat kesehatan lansia dapat meningkat.

\section{PENUTUP}

\section{Kesimpulan}

Dari hasil penelitian yang dilakukan di Pusat Pelayanan Sosial Lanjut Usia Mappakasunggu Kota Pare-Pare dengan 20 sampel diperoleh kesimpulan bahwa :
1. Sebelum dilakukan aktivitas jalan pagi, dilihat dari durasi waktu selama 30 menit yang paling banyak yakni TD sistol pre test yang hipertensi sebanyak 9 orang $(45,0 \%)$ dan TD diastol pre test yang hipertensi sebanyak 7 orang $(35,0 \%)$, sedangkan TD sistol dan diastol post test masing-masing sama yakni yang tidak hipertensi sebanyak 10 orang $(50,0 \%)$

2. Setelah dilakukan aktivitas jalan pagi dengan durasi waktu selama $<30$ menit, sistol dan diastol pre test masing-masing sama yakni yang hipertensi sebanyak 8 orang $(40,0 \%)$ sedangkan TD sistol post test yang tidak hipertensi sebanyak 1 orang $(5,0 \%)$ dan TD diastol post test yang tidak hipertensi sebanyak 2 orang $(10,0 \%)$.

3. Jalan pagi selama 30 menit dengan frekuensi 4 kali dalam seminggu sangat berpengaruh terhadap menurunnya tekanan darah sistolik dan diastolik pada lansia penderita hipertensi.

\section{Saran}

Berdasarkan hasil penelitian yang dilakukan dapat diberikan beberapa saran kepada pihak yang terkait yang berhubungan dengan :

1. Diharapkan dapat menambah ilmu pengetahuan khususnya di bidang keperawatan gerontik dan memberi sumbangan ilmiah serta merupakan sebagai salah satu bahan bacaan bagi peneliti selanjutnya.

2. Diharapkan kepada institusi kesehatan untuk mengajak dan mengajarkan terapi non farmakologi yakni aktivitas jalan pagi yang merupakan salah satu upaya untuk menurunkan tekanan darah pada penderita hipertensi.

3. Diharapkan peneliti dapat menambah pengetahuan yang praktis kepada peneliti selanjutnya tentang aktivitas jalan pagi terhadap tekanan darah pada penderita hipertensi.

4. Diharapkan dapat menjadi sumber informasi dan layanan perawatan yang benar bagi masyarakat khusunya penderita hipertensi dalam menurunkan tekanan 
darah menggunakan terapi non farmakologi.

\section{DAFTAR PUSTAKA}

1. Adam, L. (2019). Determinan hipertensi pada lanjut usia. 1(2), 82-89.

2. Anastasya, A. G., Nelwan, J. E., \& Wariki, W. M. (2018). Kejadian Hipertensi Dan Riwayat Keluarga Menderita Hipertensi Di Puskesmas Paceda Kota Bitung. Jurnal KESMAS Vol. 7 No. 5 , 1-5.

3. Aspani Yuli Reny. (2014). Buku Ajar Keperawatan Gerontik Aplikasi NANDA NIC DAN NOC Jilid 1. (T. A. Maftuhin, Ed.) (1st ed.). Jakarta: TIM.

4. Azizah, L. M. (2011). Keperawatan Lanjut Usia. Yogyakarta: Graha Ilmu.

5. Azmi, N., Karim, D., \& Nauli, F. A. (2014). Gambaran Kualitas Hidup Lansia Dengan Hipertensi Di Wilayah Kerja Puskesmas Sidomulyo Kecamatan Tampan Pekanbaru, 439-448.

6. Bustan, M. N. (2015). Manajemen Pengendalian Penyakit Tidak Menular. Jakarta: PT RINEKA CIPTA.

7. Dewi, I. G. (2019). Aktivitas Fisik Masyarakat Urban di Jakarta Selatan. Hasanuddin Journal of Midwifery, Volume 1(Issue 1).

8. Harahap, R. A., Rochadi, R. K., \& Sarumpaet, S. (2017). Pengaruh Aktivitas Fisik Terhadap Kejadian Hipertensi Pada Laki-laki Dewasa Awal (18-40 Tahun) Di Wilayah Puskesmas Bromo Medan Tahun 2017. Jurnal Muara Sains, Teknologi, Kedokteran, dan Ilmu Kesehatan Vol. 1, No. 2 , 68-73.

9. Iswahyuni, S. (2017). Hubungan Antara Aktifitas Fisik Dan Hipertensi Pada Lansia. PROFESI, Volume 14, Nomor 2, 1-4.

10. Karim, N. A., Onibala, F., \& Kallo, V. (2018). Hubungan Aktivitas Fisik Dengan Derajat Hipertensi Pada Pasien Rawat Jalan Di Wilayah Kerja Puskesmas Tagulandang Kabupaten Sitaro, 6, 1-6.

11. Kementrian Kesehatan RI. 2019. Riset Kesehatan Dasar. Jakarta: Kemenkes RI. Diakses pada tanggal 10 Juni 2020 dari http://p2ptm.kemkes.go.id/kegiatan- p2ptm/pusat-/hari-hipertensi-dunia-2019know-your-number-kendalikan-tekanandarahmu-dengan-cerdik

12. Larasiska, A., \& Priyantari, W. (2017). Menurunkan Tekanan Darah dengan Cara Mudah pada Lansia, 1(2), 55-63.

13. Longo, D. (2012). Harrison's Principles of Internal Medicine. USA: McGraw Hill.

14. Manuntung, A. (2018). Terapi Perilaku Kognitif Pada Pasien Hipertensi. Yogyakarta: Wineka Media.

15. Musfirah, \& Masriadi. (2019). Analysis of Risk Factor Relation With Hypertension Occurrence At Work Area of Takalala, 2(2), 94-102.

16. Puspitasari, D. I., Hannan, M., \& Chindy, L. D. (2017). Pengaruh Jalan Pagi Terhadap Perubahan Tekanan Darah Pada Lanjut Usia Dengan Hipertensi Di Desa Kalianget Timur Kecamatan Kalianget Kabupaten Sumenep, 5(2), 169-177.

17. Redaksi. (2010). Sehat Dan Bugar DI Usia Lanjut. Yogyakarta: Banyu Media.

18. Rahadiyanti, L. (2013). Hubungan Kebiasaan Berolahraga Jalan Kaki Dengan Kontrol Tekanan Darah Pada Pasien Hipertensi. Jakarta: Universitas Negeri Islam Syarif Hidayatullah

19. Santoso, D. (2010). Membonsa Hipertensi. Surabaya: Jaring Pena.

20. Saputra, L. (2013). Pengantar Kebutuhan Dasar Manusia. Tangerang selatan: Binarupa Aksara.

21. Sari, A. (2018). Pengaruh Aktivitas Fisik Jalan Pagi Terhadap Tingkat Hipertensi Lansia Di Dusun Biru Trihanggo Gamping Sleman. Jurnal Unisa.

22. Shadine, M. (2010). Mengenal Penyakit Hiperetnsi, Diabetes, Stroke dan Serangan Jantung. Keenbooks.

23. Solon, M., Linggi, E., Siki, S., \& Toding, S. (2019). Pengaruh Latihan Jalan Cepat Terhadap Penurunan Tekanan Darah Pada Pasien Hipertensi Di Puskesmas Jongaya Makassar, VIII(March 2018), 221-230.

24. Surbakti, S. (2014). Pengaruh Latihan Jalan Kaki 30 Menit Terhadap Penurunan Tekanan Darah Pada Pasien Penderita Hipertensi Di Rumah Sakit Umum Kabanjahe. JURNAL Pengabdian Kepada Masyarakat Vo. 20 Nomor 77, 1-13. 
25. Sunaryo, Wijayanti, R., Kuhu, M. M., Sumedi, T., Widayanti, E. D., Sukrillah, U. A., Kusmawati, A. (2016). Asuhan Keperawatan Gerontik. Yogyakarta: CV. Andi Offset.

26. Syadiyah, H. (2018). Keperawatan Lanjut Usia. Sidoarjo: Pindomedika Pustaka.

27. Utami, G. T., Utomo, W., \& Riolita, M. (2016). Analisis tekanan darah lansia yang melakukan kegiatan olahraga jalan pagi, 6(1).

28. Wijaya, A. S., \& Putri, Y. M. (2013). Keperawatan Medikal Bedah I Keperawatan Dewasa teori dan Contoh Askep. Yogyakarta: Nuha Medika. 